\title{
Spatial vulnerability units - expert-based spatial modelling of socio-economic vulnerability in the Salzach catchment, Austria
}

\author{
S. Kienberger, S. Lang, and P. Zeil \\ Centre for Geoinformatics (Z_GIS), Salzburg University, Schillerstrasse 30, 5020 Salzburg, Austria \\ Received: 11 February 2009 - Revised: 8 May 2009 - Accepted: 13 May 2009 - Published: 19 May 2009
}

\begin{abstract}
The assessment of vulnerability has moved to centre-stage of the debate between different scientific disciplines related to climate change and disaster risk management. Composed by a combination of social, economical, physical and environmental factors the assessment implies combining different domains as well as quantitative with qualitative data and makes it therefore a challenge to identify an integrated metric for vulnerability. In this paper we define vulnerability in the context of climate change, targeting the hazard "flood". The developed methodology is being tested in the Salzach river catchment in Austria, which is largely prone to floods. The proposed methodology allows the spatial quantification of vulnerability and the identification of vulnerability units. These units build upon the geon concept which acts as a framework for the regionalization of continuous spatial information according to defined parameters of homogeneity. Using geons, we are capable of transforming singular domains of information on specific systemic components to policy-relevant, conditioned information. Considering the fact that vulnerability is not directly measurable and due to its complex dimension and social construction an expert-based approach has been chosen. Established methodologies such as Multicriteria Decision Analysis, Delphi exercises and regionalization approaches are being integrated. The method not only enables the assessment of vulnerability independent from administrative boundaries, but also applies an aggregation mode which reflects homogenous vulnerability units. This supports decision makers to reflect on complex issues such as vulnerability. Next to that, the advantage is to decompose the units to their underlying domains. Feedback from disaster management experts indicates that the approach helps to improve the design of measures aimed at strengthening preparedness and mitigation.
\end{abstract}

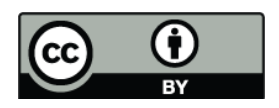

Correspondence to: S. Kienberger (stefan.kienberger@sbg.ac.at)
From this point of view, we reach a step closer towards validation of the proposed method, comprising critical useroriented aspects like adequateness, practicability and usability of the provided results in general.

\section{Motivation and background}

In order to monitor and to capture vulnerability from a decision maker's point of view, appropriate means of quantification and visualization have to be available. One of the major objectives of assessing risk - and hazard and vulnerability, respectively - is to understand the complex interaction of drivers with the aim to identify hotspot areas. Once the location of those areas of anomalous vulnerability is identified, actors can plan and implement measures required to mitigate the negative impacts of imminent hazards. The challenge for a workable concept of vulnerability is to quantify a phenomenon which we cannot directly "see", "feel" or measure directly through a single indicator. Composed by a combination of social, economical, physical (e.g. built infrastructure) and environmental (e.g. ecosystem related) factors the assessment implies combining different domains as well as integrating quantitative and qualitative data. Available assessments often target different scale levels - ranging from global to local - where a majority is based on political or administrative boundaries. The resulting entity is a legally homogenous unit, characterized by legal fiat boundaries (Smith, 1995) that potentially obscure possible internal patterns reflecting spatial discontinuity of any other spatial phenomena. Policy-related decisions based on this information may be misleading and yield unwanted impacts. The concept of modifiable areal unit problem (MAUP) and the related effect of "ecological fallacy" (Openshaw, 1984) have been often discussed within the context of spatial representation and modeling: the first term explains the fact that any spatial information depends on the underlying logic of

Published by Copernicus Publications on behalf of the European Geosciences Union. 


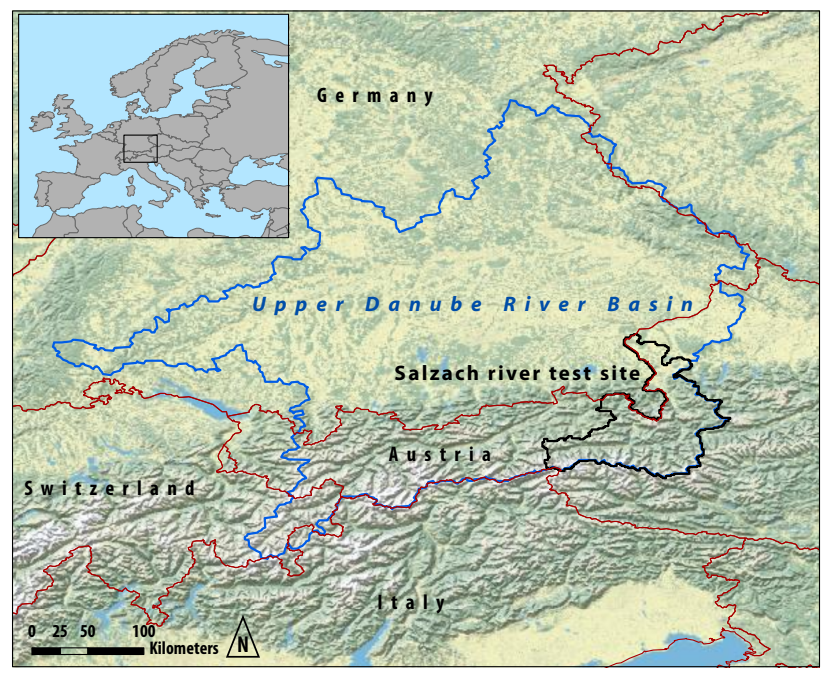

Fig. 1. Location of the Austrian Salzach River case study area within the Upper Danube River Basin and Central Europe.

unit delineation, while the latter metaphorically illustrates the problem of a collective treatment of all elements belonging to that given unit. In order to minimize the unit-related biases, we will present a method for identifying and automatically delineating concept-related fiat boundaries (Smith and Mark, 1998) for vulnerability units. This paper discusses a spatial explicit model for assessing socio-economic vulnerability to flood hazards at the sub-national level and independent from administrative boundaries.

Within hydrological modeling approaches, Flügel (1996) proposed the delineation of hydrological response units (HRU's) which comprise a specific assembly of components characterizing the catchment's natural environment. In the context of the DPSIR-Framework (Driving forces, Pressures, States, Impacts and Responses; Smeets and Weterings, 1999; EC, 2002a, b, c), Integrated Water Resources Management (IWRM) and the integration of environmental, physical and socio-economic domains, the derivation of systemic Water Resource Response Units (WRRUs) has been proposed. The spatial modeling of vulnerability units (VulnUs, Kienberger et al., 2008) follows a conceptualization developed within this research context and has been tested by analyzing the flood hazard in the Salzach river catchment (Austria).

\subsection{Case study: Salzach river catchment (Austria)}

The research has been carried out in the Austrian part of the Salzach river catchment (see Fig. 1). As one of the main tributaries of the Inn River (sub-catchment of the Danube Basin), the Salzach drains a large part of the Eastern Alps in Austria. Along its total length of $225 \mathrm{~km}$ the Salzach collects waters from a catchment area of $6649 \mathrm{~km}^{2}$ within an altitude range of almost $3000 \mathrm{~m}$ (highest point Großvenediger: $3666 \mathrm{~m}$, river mouth: $389 \mathrm{~m}$ ). The catchment is charac- terised by an alpine regime at the headwaters and the middle reaches, and pre-alpine dominated areas at its lower course. The alpine areas comprise the Hohe Tauern mountain range dominated by crystalline rocks which are in parts protected by the National Park Hohe Tauern (IUCN category II). However, outside of the protection zones the area is characterised by long established cultural landscapes (alpine pastoral systems), structural transformations by a demanding tourism sector (especially winter tourism/skiing) and the infrastructure for hydropower generation. The highest areas are dominated by glaciers and permafrost, depending on aspect, starting at altitudes of $2600 \mathrm{~m}$ (Lieb, 1998; Ebohon and Schrott, 2008). North of the Hohe Tauern the greywacke zone, a band of palaeozoic sedimentary rocks, forms ridges with a smooth morphology. This zone comprises the major skiing resorts of the Eastern Alps and is extensively used for timber production. The source of the Salzach River lies within this zone, which is not glaciated and shows no evidence of permafrost. Further to the North, the Northern Limestone Alps follow a west-east trend characterised by a more rugged landscape. Sedimentary rocks can be found in the lower course and valley floors, a terrain which is predominately used for dairy farming. This highly dynamic area, with the City of Salzburg as its major centre, lies at the crossroad of important trading routes and transportation networks. In general the whole test site area is less dominated by industrial production and is more oriented towards tourism and services provision.

The test site has a total population of approximately 454000 inhabitants, whereas most of the people live in the city of Salzburg (approx. 150000 inhabitants) and its surroundings. The population distribution concentrates on the valley floors with a strong dominance in the major Salzach river valley. The climate zones comprise high mountain regimes in the upstream areas and moderate continental conditions in the lowlands. The northern areas receive a large amount of precipitation (around $1120 \mathrm{~mm}$, City of Salzburg) due to the blocking effect of the Alps, which reaches up to $1400 \mathrm{~mm}$ in the inner-alpine Salzach valley and up to $1600 \mathrm{~mm}$ at the Sonnblick observatory.

Hazards in the test site area include floods, landslides, avalanches, debris flow and flash floods. This research study focuses only on river flood hazard, as it is more adequate to address a single type of hazard when identifying appropriate indicators. A characteristic of the Salzach river is its regulated river course, which has been modified since the early 19th century. Currently efforts are being made to reregulate the river course, especially in the lower course, due to increased riverbed erosion. Recent floods took place in 2002 (with $2300 \mathrm{~m}^{3} / \mathrm{s}$ water flow in the city of Salzburg; HQ100) and 2005 with a total damage of 48 mill EUR in 2002 (Stalzer, 2003). 


\subsection{Defining vulnerability in the context of water and climate change issues}

The concept of vulnerability as a descriptor of the status of a society or community with respect to an imposed hazard or threat is deeply rooted in a multidisciplinary research effort. This research work has been discussed and outlined in Clark et al. (2007) and Kienberger et al. (2009), and focuses on the socio-economic domain of vulnerability by considering climate change induced effects.

The concept of vulnerability has been widely discussed in literature, and recent reviews by Villagrán (2006) and Birkmann (2006) draw together some highlights of a range of opinions. In regard to the assessment and reduction of socioeconomic vulnerability to climate induced hazards, different research and policy communities representing disaster risk reduction, climate change adaptation, environmental management and poverty reduction have taken up the discussion (Thomalla et al., 2006). In the economic domain, monetary loss estimations focussing on single hazards can be found (e.g., Oberndorfer at al., 2007). However, a consensus on a more integrative approach has not yet been achieved and even within the climate change community divergent notions of vulnerability do exist. For example, the "end point" definition (Bogardi et al., 2005) sees vulnerability as the residual of climate change impacts reduced by adaptation (the remaining segments of the possible impacts of climate change that are not targeted through adaptation). In contrast, the "starting point" views vulnerability as a general characteristic of societies generated by different social and economic factors and processes (ibid.). Furthermore, it should also be mentioned that yet another approach, originating from UN/ISDR (2004), classifies vulnerability in different dimensions or components (social, economic, physical and environmental).

The "starting point" considers the core concept embodied in the IPCC's implicit definition of vulnerability as the degree to which a system is susceptible to, or unable to cope with, the adverse effects of climate change (IPCC, 2001a and b). The IPCC definition is a function of the character, magnitude and rate of climate change to which a system is exposed, its sensitivity (degree to which a system is affected, adversely or beneficially, by climate-related stimuli) and its adaptive capacity (the ability of a system to adjust to climate change, moderate potential damages, take advantage of opportunities or cope with the consequences). The relation can be expressed as:

$V=f(H, S, A C)$

where $H$ defines hazard, $S$ sensitivity and $A C$ adaptive capacity.

The definition suggests that vulnerability reflects the sum of the hazards (defined as a potentially damaging physical event) to which a society or community is exposed, mitigated by its adaptive or coping capacity (its ability to respond effectively to risk) and compensated by the available alternative economic opportunities. Despite the huge range of possible expressions, applicability suggests that Eq. (1), as derived from the IPCC, provides a viable initial working definition - but in practice it is difficult to implement locally. Particularly in data-poor regions, due to the fact that it includes the full range of both bio-physical and socio-economic factors (hazard and adaptive capacity), the approach is hard to realize. However, it can be suggested that the hazard term in Eq. (1) in effect serves mainly to scale the variability of the vulnerability, providing the very important spatial and temporal dimension. Thus, for any one particular place, time and hazard, it may be possible to simplify the relationship to

$V_{H}=f_{H}(S, A C)$

where hazard $(H)$ refers to the hazard concerned (flood, bank erosion, glacier lake outburst, drought etc.). The hazard here refers to the magnitude and frequency relationship (e.g. HQ50, HQ100), whereas vulnerability is not related to this process.

The IPCC definition of sensitivity as the degree to which a system is affected, adversely or beneficially, by climaterelated stimuli suggests that at heart the degree of impact is driven by risk and mitigated by adaptive capacity. However, this is a very data demanding approach which also leads to a circular argument with Eq. (1). In terms of practical application, it is therefore proposed that the definition should be built from a series of components (which relate to the sectors proposed by Villagrán, 2006):

$S=f\left(s_{1}, s_{2}, \ldots, s_{n}\right)$

where $s_{1}$ reflects livelihood susceptibility, $s_{2}$ infrastructure susceptibility and $s_{n}$ other susceptibility sectors.

For the purposes of this study, adaptive capacity is the preferred term as it relates most effectively to the concept of adaptive management and is more easily generalised to reflect society's ability to grasp opportunities as well as respond to threats. In practical terms, it is necessary to define adaptive capacity in a way which is amenable to implementation with available data sets:

$A C=f(S C, R)$

where $S C$ defines social capacity and $R$ resilience.

Resilience is here defined as the ability of a system to restore its attributes and functions to the status before an impact or pressure occurred, which can be regarded as incorporating coping capacity (Thywissen, 2006). In practice, the distinction between social capacity and resilience is one of convenience. Social capacity refers to a set of prevailing acquired dimensions of a society's working practice - and the working structures through which these capabilities are organized and delivered (e.g. skills, technologies, information, governance). Note that, next to spatial variation, the above defined 


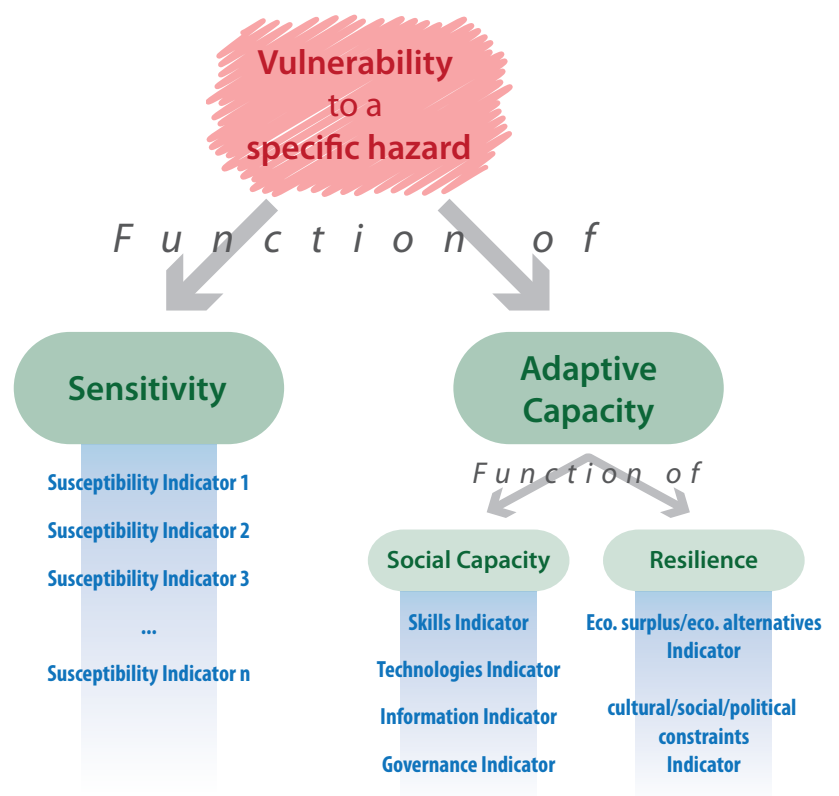

Fig. 2. Conceptualisation of vulnerability, describing its subdomains and indicator levels (Kienberger et al., 2009).

functional components of vulnerability also show a temporal dynamic (discussed in Hufschmidt et al., 2005), which is not reflected in the context of this paper.

The overall concept of vulnerability, its relation to hazard and risk $(R)$ is defined by the widely applied relationship

$R=H \times V$

The vulnerability model applied in this research context is summarised in Fig. 2. A major objective of applying this hierarchical concept is to allow the identification of indicators for each domain.

\section{Integrated spatial indicators}

\subsection{Place-based modelling of vulnerability}

Apart from the conceptualisation of vulnerability and the composition of indices/metrics the spatial modelling of vulnerability is not always regarded as a central element. However, vulnerability is - next to its multidisciplinary character - a phenomenon which is strongly related to the specifics of a place, i.e. place-based (e.g. Cutter et al., 2008, November 2008). Different researchers have focussed on this issues at the global or national scale (e.g. Turner et al., 2003; Dilley et al., 2005; Schneiderbauer, 2007). A recent comparison of various social vulnerability indicators, targeting the global or national scale, has been investigated by Gall (2007) and a validation of social vulnerability in the context to river-floods in Germany been presented by Fekete (2009).
One of the earliest works which stresses a significant place based concept of vulnerability has been published by Hewitt and Burton (1971) and further developed by Cutter et al. (2000). This work describes an index which is linked to the hazard-and-place model of vulnerability, whereas indicators reflecting the bio-physical and social vulnerability are combined to describe the place-vulnerability (Cutter, 1996). The authors combine different indicator datasets through intersecting the different data layers. Data is combined without a specific weight. The issue of assigning equal weights is being discussed within a note. It is being justified because reliable damage estimates do not exist and a way for simplification has been intended. Cutter et al. (2000) point out that further research is required to develop weighting schemes for the combination of social and bio-physical indicators and to test their relative importance in statistically predicting vulnerability. Additionally, the hazard-of-place model has been currently extended by Cutter et al. (2008) to integrate also antecedent factors and links to mitigation and preparedness. Reflecting on the hazard-of-place model Collins et al. (2008) modeled vulnerability for cities in Mexico and the USA. According to the authors, required data is available to allow a comparison of transnational vulnerabilities and highlighted the real-world relevance for planners, managers and decision-makers. Challenges arise around specific issues within the social vulnerability index (e.g. racial/ethnic minority components). They further point out that such a disaggregated vulnerability metric provides decision makers at the local level with appropriate information to identify specific shortcomings.

\subsection{The geon concept}

Monitoring a society's characteristics (and their changes over time) relevant to disaster risk reduction such as vulnerability, resilience, stability and mitigation relies on methods to evaluate the dynamics of systemic emergent properties in a holistic manner (Lang et al., 2008). Ambitiously, but soundly established, a mapping and monitoring concept for vulnerability can enable a synthetic view and be capable to integrate separately collected compartments of information (Fig. 3), regarding the respective status of soil, land use, water, etc. (mimicking the horizontal concept of geographic data layers, as established by Alfred Hettner in the early 20th century and integrated in GIS work modes so effectively). As a key element for the methodological approach, we use the geon concept as introduced by Lang (2008). The term is used to describe generic spatial objects that are homogenous in terms of changing spatial phenomena under the influence of, and partly controlled by, policy actions. The geon concept acts as a framework for the regionalization of multi-dimensional continuous spatial information according to specified parameters of homogeneity (see Sect. 3.2 for more specific discussion). It is an automated zoning approach for delineating units where similar spatial conditions apply with respect to 


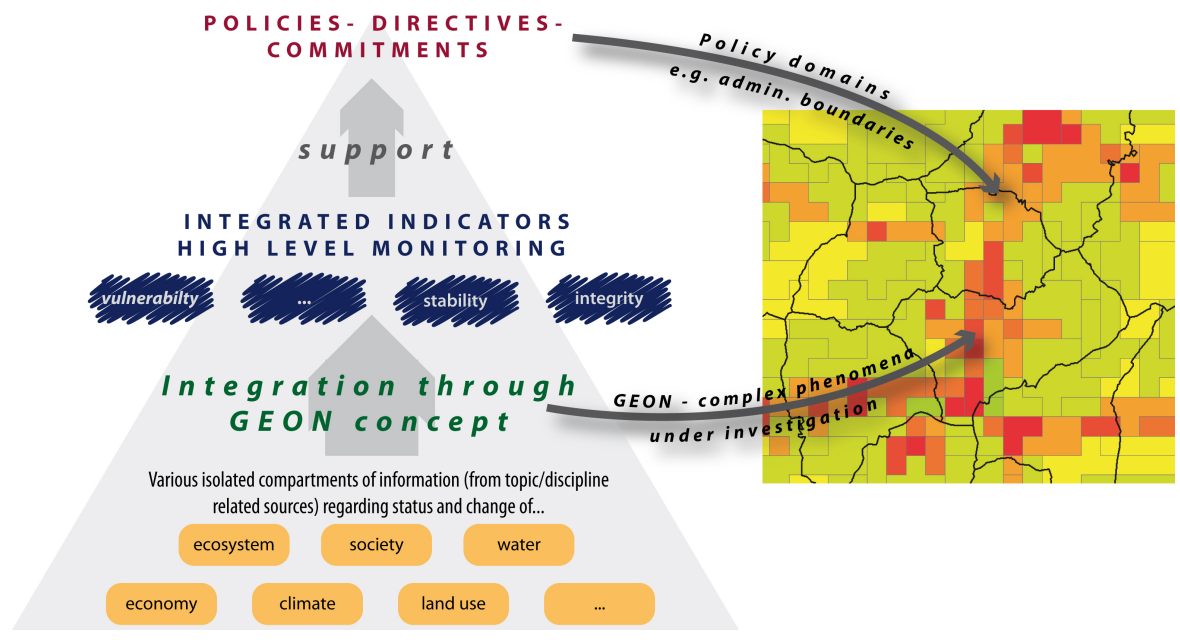

Fig. 3. The geon concept - integration of various compartments of information to model complex phenomena and provide policy relevant information (Lang et al., 2008).

an aggregated spatial indicator. Take for example hazard zoning, entrenched since several decades in spatial planning regulations in mountainous regions in Austria. This zoning exercise, performed by experts based upon a set of criteria, aims at delineating homogenous regions with uniform exposure to terrain-induced risks. In our diction such a zone can be considered a geon, because it has a limited, policy-related extent, and is constructed conceptually by integrating a range of single indicators (distance to slopes and/or rivers and/or retention areas, terrain, land cover, soil conditions, distance to existing settlements etc.). The geon concept is flexible in terms of a certain conceptualisation of a problem (specific policy realm, specific hazard domain, etc.). Using geons, we are capable of transforming singular domains of information on specific systemic components to policy-relevant, conditioned information (Tiede and Lang, 2009). Conditioned information means information which is integrated and adapted to a policy-defined realm. The step from data to information has been accomplished in most application domains: basically loads of various datasets were turned into information - information which is readily available, but - more often than not - restricted to its own domain.

Geons are generated by transforming continuous spatial information into discrete objects by algorithms for interpolation, segmentation, regionalization, generalization; they are analyzed in terms of their arrangement, which leads to emergent spatial qualities; they are dynamic and can be monitored in terms of changes. Within the spatial extent in which a certain policy applies or a certain hazard may occur, a group of geons constitutes a spatially exhaustive set (geon set). In this study, vulnerability units have been derived as a specific case of a geon set within an area exposed to flood hazard (Lang et al., 2008).
The spatial limit of the geon set, since being derived functionally, may not fully coincide with administrative boundaries. The average size of a geon depends on the scale relevant for policy implementation. Geons can always be spatially aggregated or disaggregated to administrative units, which in most cases form the spatial constraint of authorities' mandates.

\section{Methodology}

\subsection{Workflow and expert knowledge}

A specific aim of the developed methodology is to derive spatial homogenous units of vulnerability as a specific case of a geon set (Kienberger et al., 2008). Considering the fact that vulnerability is not directly measurable and due to its complex dimension and social construction an expert-based approach has been chosen. Established methodologies such as Multicriteria Decision Analysis, Delphi exercises and new approaches are being integrated to model the spatial distribution of a complex phenomenon (Fig. 4).

In an initial step, appropriate indicator datasets have been selected with the help of expert knowledge. This step depended on data availability and coverage. For the study area, these data were mainly provided by the Government of Salzburg through its public GIS database. Data used, range from infrastructure, administrative boundaries, to different socio-economic parameters such as the size of companies, means of subsistence, age distribution and workforce in economy sectors, origin and education level of the population. They originate from the census survey in 2001 and are not only provided on the basis of different administrative units, but additionally in a standardized grid format (e.g. 


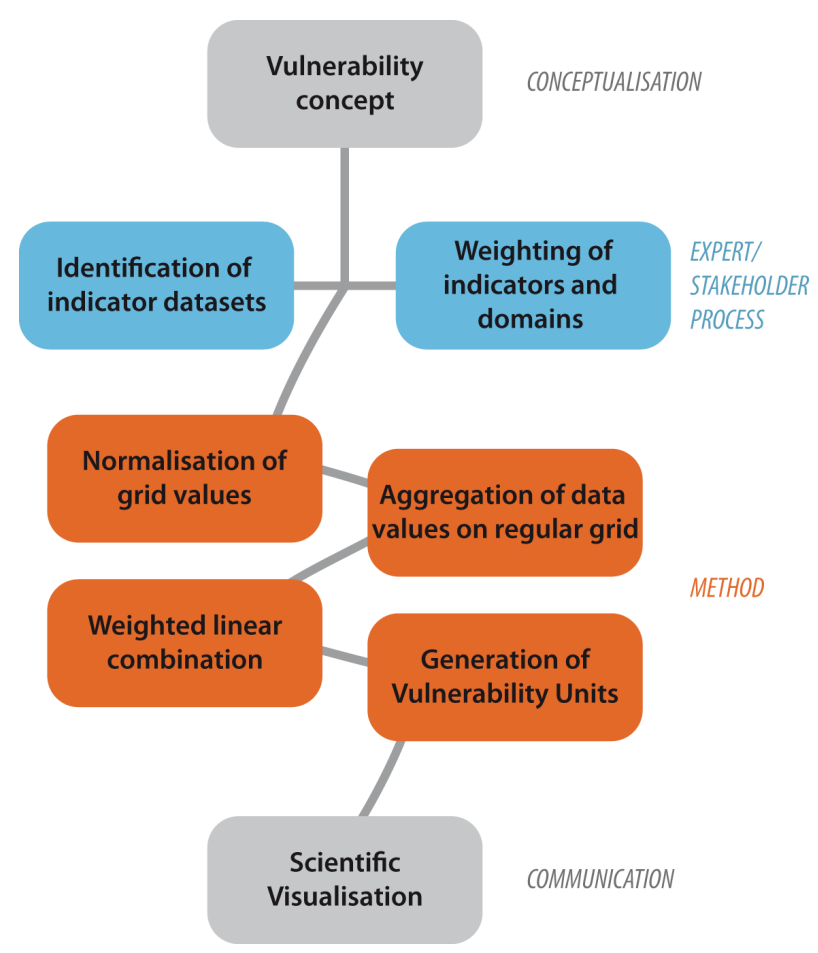

Fig. 4. Overall workflow from conceptualisation, indicator development and stakeholder process to methodological issues and communication of results.

$100 \mathrm{~m}$ grid cell size; Wonka, 2006). This is a very unique approach and allows the visualization of data in their spatial distribution independent from "artificial polygons". Another advantage is that in subsequent analysis steps MAUP is minimized. The relevance of factors such as the level of education and the origin of the population was debated in the context of the study. However, reflecting on issues raised during the Hurricane Katrina event, where merely marginalized groups have been most vulnerable (Cutter, 2005), these datasets were retained for evaluation.

Data on critical infrastructure, such as length of highways per grid cell, land use/land cover areas and indicators targeting ecosystem integrity within the resilience sub-domain (such as the protection status and availability of flood retention areas), are aggregated on the standardized grid cell. The domain "silent" land cover consists of indicators on specific land use/land cover classes to which no vulnerable elements have been directly attached (Kienberger et al., 2009). The chosen sub-domains for the vulnerability concept are identified in Table 1.

\subsection{Integration of indicators}

For integrating the different indicator data and to aggregate them on a sub-domain level, Multi Criteria Analysis (MCA), Multi Criteria Evaluation or Analytical Hierarchy Process

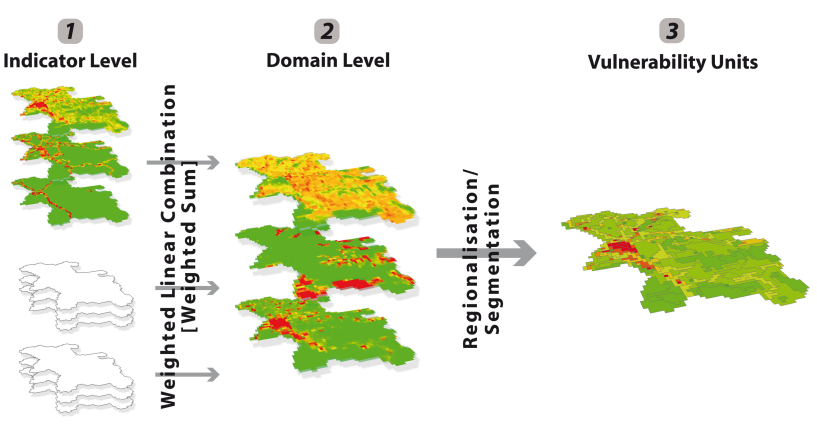

Fig. 5. Workflow to generate vulnerability units at the different levels (indicator level [1], domain level [2] and final vulnerability units [3]).

(AHP) were applied. Multi Criteria Evaluation combines information from several criteria to create a single index. A profound discussion on that topic and current best practices approaches are available in Carver, 1991; Malczewski, 1999; Malczewski, 2000; Jiang and Eastman, 2000; and Robinson, 2003. It is proposed to use common methodologies for group decision making such as scoring, ranking, pair-wise comparison or Delphi exercises to identify possible functions for the normalization of the values and weights for the different data layers. Beinat (1997) discusses the identification of the value function in depth, which allows the non-linear normalization of data. As discussed in the papers by Cutter et al. (2000) and Collins et al. (2008) the allocation of weights is a critical issue as data on verification of disasters is not available for this multidisciplinary approach. Linked to the method of MCA, scoring exercises are generally applied. Furthermore Greiving et al. (2006) argue that the Delphi method allows the integration of expert knowledge which may reflect the specific situation and circumstances for the investigated area. The Delphi method (Helmer, 1966) is based on a process of collection and integration of knowledge from experts and stakeholders through iterative and anonymous investigation of opinions by means of questionnaires and scoring.

To allow the integration and comparison of different data sets and data sources normalization has to be applied. The following linear function (Eq. 6) describes the normalization

$v^{\prime}=\frac{v-\min }{\max -\min }\left(\max _{\text {norm }}-\min _{\text {norm }}\right)+\min _{\text {norm }}$

where max and min values derive from the old value range, $\max _{\text {norm }}$ and $\min _{\text {norm }}$ define the new value range. In general, a value range between 0 and 1 is utilized. For this case study, an 8 bit value range $(0-255)$ has been applied to make use of the full radiometric spectrum of raster datasets. To allow further comparisons the layers are normalized again (Eq. 6) to allow integration of the domain level data.

In our approach we integrate the different indicator data sets (Table 1) on a domain level through weighted linear 
Table 1. Indicators and expert-derived weights (in brackets) of the different vulnerability domains.

\begin{tabular}{|c|c|}
\hline $\begin{array}{l}\text { Vulnerability } \\
\text { Domain }\end{array}$ & Single indicators (level 1) and aggregated domains (level 2) \\
\hline \multirow[t]{6}{*}{ Sensitivity } & $\begin{array}{l}\text { Susceptibility }- \text { Housing/Buildings }[0.158] \\
\text { Number of buildings per grid cell with } 1-2 \text { households }[0.3],>3 \text { households } \\
\text { per building [0.175], communal buildings [0.083], tourism relevant buildings } \\
\text { [0.5], offices [0.042], commerce [0.025], communication infrastructure } \\
\text { buildings [0.117], industry [0.108], critical infrastructure (health, education, ...) } \\
\text { [0.083], other buildings [0.017] }\end{array}$ \\
\hline & $\begin{array}{l}\text { Susceptibility - Infrastructure [0.105] } \\
\text { Length per grid cell: highways [0.1], primary roads [0.208], secondary roads } \\
\text { [0.317], railway [0.133]; number per grid cell of large power plants [0.167], small } \\
\text { power plants [0.075] }\end{array}$ \\
\hline & $\begin{array}{l}\text { Susceptibility - Assets [0.125] } \\
\text { Area per grid cell: crop [0.192], pasture [0.167], forests [0.292], reservoirs } \\
\text { [0.158]; number per grid cell: water springs [0.192] }\end{array}$ \\
\hline & $\begin{array}{l}\text { Susceptibility - "Silent" Land Cover [0.053] } \\
\text { Area per grid cell: lakes [0.444], alpine meadows [0.2], rocks/mountain peaks } \\
\text { [0.133], glaciers [0.222] }\end{array}$ \\
\hline & $\begin{array}{l}\text { Susceptibility }- \text { Population: age distribution }[0.073] \\
\text { Number per grid cell: population aged }<20 \text { years }[0.292], 20-80 \text { years } \\
{[0.333] \text { and }>80 \text { years }[0.375]}\end{array}$ \\
\hline & $\begin{array}{l}\text { Susceptibility - Population: means of subsistence [0.043] } \\
\text { Number per grid cell: full time employment male [0.211]/female [0.211], half } \\
\text { time male [0.178]/female [0.178], precarious employment male } \\
{[0.111] / \text { female }[0.111]}\end{array}$ \\
\hline \multirow[t]{7}{*}{ Adaptive Capacity } & $\begin{array}{l}\text { Resilience - Workforce in economy sectors [0.065] } \\
\text { Number of employees per grid cell: agriculture [0.342], mining [0.175], } \\
\text { production [0.225], services [0.258] }\end{array}$ \\
\hline & $\begin{array}{l}\text { Resilience - Size of companies/workplaces [0.040] } \\
\text { Number of companies per grid cell with: }<49 \text { [0.5], 50-249 [0.25], > } 250 \\
\text { employees }[0.25]\end{array}$ \\
\hline & $\begin{array}{l}\text { Resilience - Ecosystem integrity [0.105] } \\
\text { Area per grid cell: protected areas [0.417], retention areas [0.583] }\end{array}$ \\
\hline & $\begin{array}{l}\text { Resilience - Access [0.050] } \\
\text { Distance per grid cell to: health facilities [0.458], roads [0.542] }\end{array}$ \\
\hline & $\begin{array}{l}\text { Social Capacity - Early Warning [0.125] } \\
\text { Early warning system available [0.556], number of first responders per grid cell [0.444] }\end{array}$ \\
\hline & $\begin{array}{l}\text { Social Capacity - Origin of population [0.015] } \\
\text { Number per grid cell from Austria [0.333], EU [0.333], } \\
\text { other countries [0.333] }\end{array}$ \\
\hline & $\begin{array}{l}\text { Social Capacity - Education [0.045] } \\
\text { Number per grid cell: academics [0.458], non-academics [0.542] }\end{array}$ \\
\hline
\end{tabular}


combination (see Fig. 5). Therefore the raster datasets are multiplied by a weight and finally summed up (Eq. 7).

$V\left(x_{i}\right)=\sum_{j} w_{j} v_{j}\left(x_{i}\right)=\sum_{j} w_{j} r_{i j}$

The weights have been derived from a scoring exercise with four stakeholders and experts, who have significant expertise in the field of disaster risk reduction and regional planning in the Salzach catchment. The experts, ranging from practitioners (government and NGOs) to academics, have been asked to distribute a predefined amount of scores to each of the factors according to their relative importance and contribution to the vulnerability of people in the Salzach for floods. The identified weights are listed in Table 1. Two hierarchical levels have been applied to allow for appropriate investigation and flexibility within the modeling (indicators - level 1, domains - level 2). On the first level 100 points had to be distributed, to derive the weights for the combination of indicators on level 2 (domain level), whereas 30 points have been distributed to allow the integration to the final vulnerability index. The exercise was facilitated through an online form, which also automatically calculated the constant sums.

From the weighted sums and its domain data sets the vulnerability units are being derived. To this end we used regionalization techniques applied to multidimensional data, as offered by object-based image analysis (OBIA, Lang and Blaschke, 2006). Borrowed from the domain of remote sensing image segmentation, we employed a region-based, local mutual best fitting approach that merges image segments according to the gradient of degree of fitting (Baatz and Schäpe, 2000). It allows for controlling two complementary criteria of similarity of neighbouring segments: likeness in "colour" or "form". Spatial objects can be generated that are rather compact or have rather smooth outlines. A scalefactor enables user-driven control of appropriate scale representations. Providing multi-resolution segmentation in a reproducible manner with a controllable average size of objects organized in a strict spatial hierarchy (scale-adaptive segmentation, Lang, 2008) is the primary objective of the object generation approach (Baatz and Schäpe, 2000).

The difference between adjacent objects (ibid.) is expressed by the spectral distance $(S D)$ of two pixels or objects $p_{1}, p_{2}$ in a feature space:

$S D=\sqrt{\sum_{d=1}^{n}\left(p_{1}-p_{2}\right)^{2}}$

or noted as vector difference for a three-dimensional feature space as:

$S D=(\underset{v 1}{\longrightarrow}-\underset{v 2}{\longrightarrow}) ;$ where $\underset{v 1}{\longrightarrow}=\left(\begin{array}{l}d 1_{1} \\ d 1_{2} \\ d 1_{3}\end{array}\right)$ and $\underset{v 2}{\longrightarrow}=\left(\begin{array}{l}d 2_{1} \\ d 2_{2} \\ d 2_{3}\end{array}\right)$

specify the feature space location of pixel 1 and pixel 2 or the average value of object 1 and object 2 .
To optimize the degree of homogeneity between two neighboring pixels or objects, the specific heterogeneity $h_{\min }$ is minimized at every merge. The current degree of fitting $\left(h_{\text {diff }}\right)$ is characterized by the change in heterogeneity in a "virtual merge" (ibid.):

$h_{\mathrm{diff}}=h_{\mathrm{min}}-\frac{S D_{1}+S D_{2}}{2}$

By additional weighting the heterogeneity criterion with object size the requirement of producing objects of similar area can be accomplished. Form homogeneity is realized by relating object boundary length (perimeter) to the perimeter of the most compact form of the same size (i.e. a circle), the deviation of which can be expressed by the shape index:

$S H P=\frac{p}{2 \sqrt{\pi * S}}$

where $p$ equals the perimeter and $s$ equals the size of an object.

As this regionalization algorithm is usually applied to spectral reflectance values, a comprehensive approach was chosen to normalize the values within the 8 bit range. The regionalization algorithm allows weighting of the different layers, which reflect the results from the stakeholder process (Table 1). In this case a scale parameter of 4 was applied with shape index of 0.5 and compactness factor of 0.1 . Finally for each unit a vulnerability value $(V)$ is calculated considering the different layers $\left(\boldsymbol{v}_{\mathbf{1}}, \boldsymbol{v}_{\mathbf{2}}, \ldots \boldsymbol{v}_{\boldsymbol{n}}\right)$ in a $j$-th dimensional space through the vector product

$$
|\vec{V}|=\sqrt{v_{1}^{2}+v_{2}^{2}+v_{3}^{2}}
$$

The results of both methods can be standardized within the range 0 and 1 , whereas 1 reflects a high and 0 a low vulnerability.

\section{Results and discussion}

The results of the vulnerability modeling are visualized as analytical 3-D view (Tiede and Lang, 2009), shown in Fig. 6. From a general perspective populated areas are the most vulnerable ones. This is due to the clear socio-economic focus (indicators on buildings, population etc.) of this study and the weighting of different indicators. Factors within the susceptibility domains "housing", "infrastructure" and "assets" and the social capacity domain "early warning" received the highest ranks. Additionally, some areas are characterized (Fig. 7) by high sensitivity and high adaptive capacity values (mostly in urban areas), which also means that units, which reflect high adaptive capacity could be characterized by high vulnerability. The reason for that is mainly due to the construction of the index as adaptive capacity does not directly out-compete sensitivity and vice versa. The various domains of sensitivity and adaptive capacity have been combined to calculate the vulnerability index, whereas the weights of the 

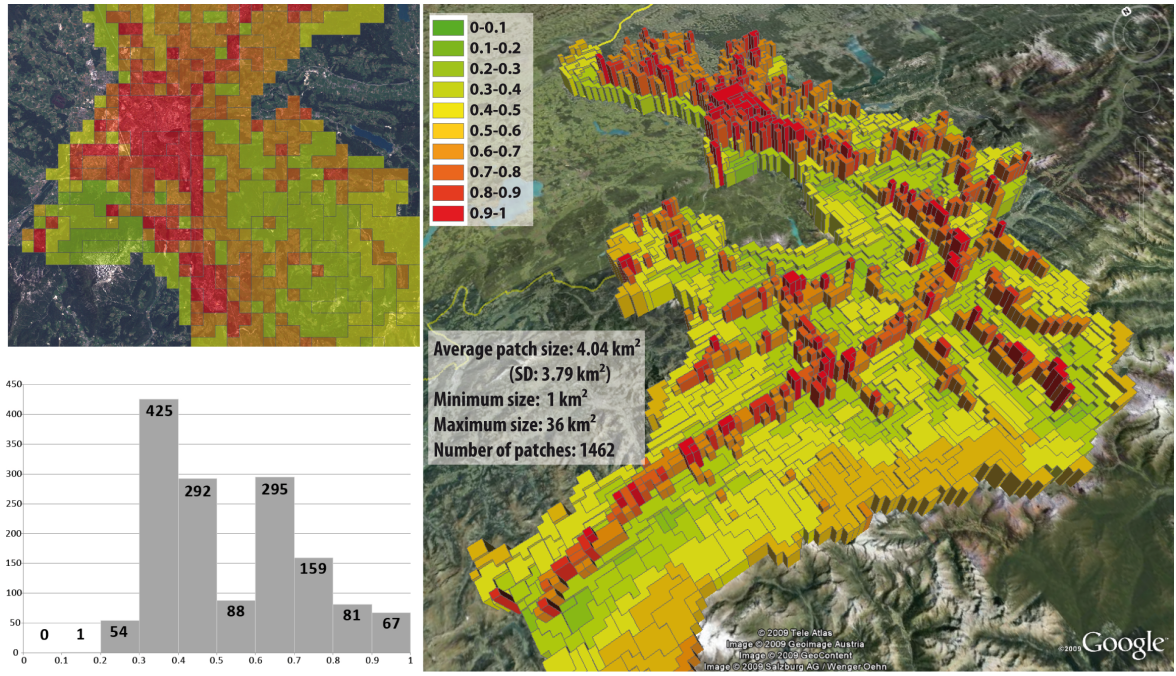

Fig. 6. Visualisation of vulnerability units (height reflects the vulnerability index) in Google Earth and as a planar map for the city of Salzburg. The degree of vulnerability is classified in 10 classes ranging from low (0) to high (1) vulnerability. The histogram indicates number of vulnerability units (VulnUs) per vulnerability class.

\section{Sensitivity}

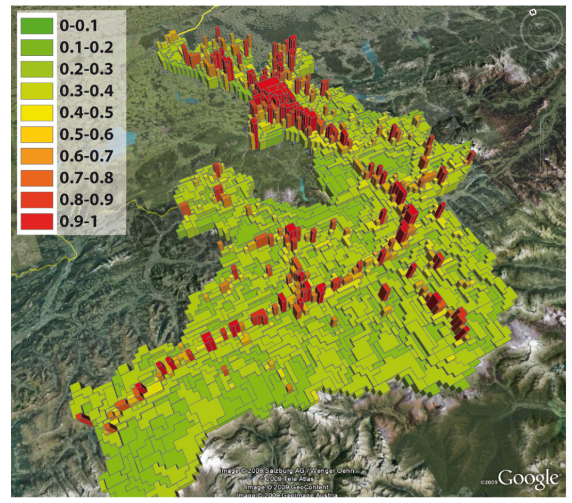

Adaptive Capacity

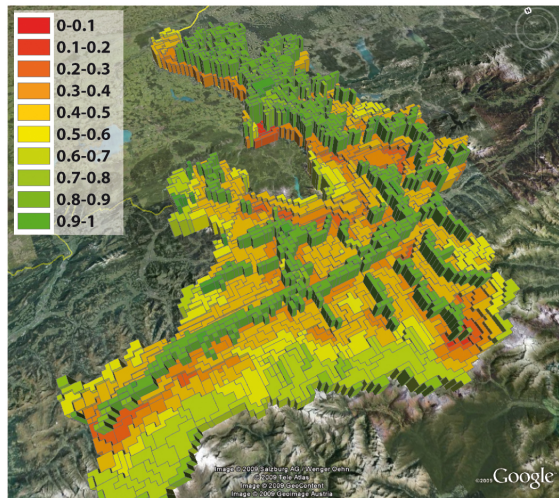

Fig. 7. Showing the sensitivity and adaptive capacity domain of vulnerability (decomposability of the geon approach).

different domains play a critical role. This issue may help to verify conceptual approaches of vulnerability for cases, where either the domains are of central interest or social constructions such as sensitivity and adaptive capacity can be directly related. The calculation of the adaptive capacity and sensitivity index (Fig. 7) has been performed separately from the vulnerability index considering only the respective domains.

The 10 most vulnerable areas are equally distributed over the test area site and are located at important local population centers reflecting shortfalls within different vulnerability domains. In total 1462 patches have been derived. The size also depends on the chosen scale factor, however allows for modifications based on the intended policy scale. An aggregation and disaggregation modality is reflected through the choice of the scale parameter. The size of the VulnUs varies from $1 \mathrm{~km}^{2}$ to $36 \mathrm{~km}^{2}$, whereas the highest number of patches falls in the class of $1 \mathrm{~km}^{2}$ sized units. This can be attributed to the heterogeneity in specific areas. Less vulnerable areas, also less populated areas, show a higher level of aggregation and reflect a higher degree of homogeneity.

The number of units per vulnerability class describes a bimodal distribution (Fig. 6), whereby the vulnerability classes 4, 5 and 7 have the highest portion. Looking from a generalized viewpoint one could also observe a normal distribution with low numbers on the extremes (vulnerability class 1 and 10).

The method allows the assessment of vulnerability independent from administrative boundaries, but also applies an aggregation mode which reflects homogenous vulnerability 
units. This supports decision makers to reflect on complex issues such as vulnerability on a sub-administrative level, but derives units which represent a common characteristic of vulnerability. Next to that, the advantage is to decompose the units into its underlying domains. In Fig. 7 decomposition into the defined vulnerability domains of sensitivity and adaptive capacity is illustrated. From an expert's point of view decomposition can be extended down to the indicator level, which allows a specific investigation of problem areas and shortcomings. We see this as a central element of our developed approach: on the one hand the integrated modeling of vulnerability for the identification of "hot spots" through homogenous vulnerability units, on the other hand the decomposability down to the specific indicator level for an expert's view.

However, it has to be considered - and this is a general challenge for the assessment of (socio-economic) vulnerability - that the relevant data have to be available. In Austria census data is provided on aggregated grid cells. Due to data privacy issues, information gaps may exist on grid cells smaller than $1 \mathrm{~km}^{2}$. This is a challenge for other countries where those datasets are not available at all, and need to be derived by e.g. statistical area disaggregation of census units using land use information (e.g. Mennis, 2003; Tiede and Lang, 2009).

As mentioned above, methodological challenges also arise from the expert based approach and the identification of weights. In general, the methodology to derive vulnerability units can be transferred to other conceptualizations as well. In this context this approach has been chosen. We are aware about the shortcomings of the expert-based approach and discussion on objectivity (such as outlined in Collins et al., 2008) relate. Still, we see this as an approach to assign relationships between the different data sets whereas other approaches lack data or cannot be implemented due to the characteristics of indicators and data (quantitative vs. qualitative; multi- and transdisciplinary approaches).

To visualize the results, the production of standard maps is possible. Within our workflow we added scientific visualization as an important element to communicate the results to decision makers. Virtual globes such as Google Earth allow the integration of these results, provide a sound basis of baseline data and allow the exploration of results through 3-D effects (Tiede and Lang, 2009).

\section{Conclusions}

In this paper we present a methodology to model the complex phenomena of vulnerability through the identification of vulnerability units. Further investigations involve the alternative way to identify weights, the integration of environmental/ecological (Leidel, 2008) domains to assess an overall vulnerability. A general issue is the verification and validation of results, which could not yet be quantitatively carried out. Verification, i.e. comparison of the result with any kind of objective "true" information, is still immature for evaluating integrated indicators mapped (such as vulnerability units) and modelled in the way described above. In the introductory part of the paper we claimed to derive vulnerability boundaries as a specific instance of concept-driven fiat boundaries. In order to verify their delineation, and especially to base decisions on their spatial distribution, it may be considered a conceptual goal to turn vulnerability units into bona fide objects as reflecting more genuine discontinuities in space (Smith, 1995). But this would require a more rigorous concept of vulnerability categories or classes with a unified, interdisciplinary notion on vulnerability - a major challenge in vulnerability science.

Considering disaster risk reduction as the ultimate objective, actors from national governments, provincial administrations and local authorities need to plan interventions based on location. By nature regional development is a highly multidisciplinary task: enacting land use change (e.g. to create retention areas along rivers or to resettle vulnerable people) involves experts from different disciplines or ministries. To implement interventions, consensus has to be reached among all stakeholders, including the vulnerable population. Without a spatial representation of the situation, visualising the extent of hazard or the distribution of vulnerability and the communication of possible risk is hard to achieve. The spatial vulnerability approach offers the opportunity to visualise susceptibility for all and facilitates the exploration of intervention options with all. First feedback from disaster management experts indicate that the approach helps to improve the design of measures aimed at strengthening preparedness and mitigation. From this point of view, we reach a step closer towards validation of the proposed method, comprising critical user-oriented aspects like adequateness, practicability and usability of the provided results in general.

Acknowledgements. The authors would like to thank M. Leidel for data processing and fruitful and critical discussions. The research leading to these results has received funding from European Community's Sixth Framework Programme (FP6, 2002-2006) under Grant Agreement Number FP 6-036952 (BRAHMATWINN - Twinning European and South Asian River Basins to enhance capacity and implement adaptive management approaches; http://www.brahmatwinn.uni-jena.de/).

Edited by: T. Glade

Reviewed by: S. Fuchs and G. Hufschmidt

\section{References}

Baatz, M. and Schäpe, A.: Multiresolution Segmentation: an optimization approach for high quality multi-scale image segmentation, in: Proceedings of the Angewandte Geographische Informationsverarbeitung XII., edited by: Strobl, J., Blaschke, T., Griesebner, G., et al., Beiträge zum AGIT Symposium Salzburg, 12-23, 2000. 
Beinat, E.: Value Functions for Environmental Management, Kluwer Academic Pub., 1997.

Birkmann, J. (ed.): Measuring Vulnerability to Natural Hazards, Towards Disaster Resilient Societies, United Nations University Press, 2006.

Bogardi, J., Villagrán, J. C., Birkmann, J., Renaud, F., Sakulski, D., Chen, X., Affeltranger, B., Mensa, A., and Kaplan, M.: Vulnerability in the context of climate change, Human Security and Climate Change, An International Workshop, Asker, Sweden, 2005.

Carver, S. J.: Integrating multi-criteria evaluation with geographical information systems. Int. J. Geogr. Inf. Sci., 5(3), 321-339, doi:10.1080/02693799108927858, 1991.

Clark, M. J., Hutton, C. W., Amoaka Johnson, F., Steyl, I., Kienberger, S., Zeil, P., and Lang, S.: Defining vulnerability Towards a conceptual model for climate change impact, Deliverable Report $\mathrm{Nr}$ 4.5, 2007.

Collins, T. W., Grineski, S. E., and Romo Aguilar, M. L.: Vulnerability to environmental hazards in the Ciudad Jua'rez (Mexico) - El Paso (USA) metropolis: A model for spatial risk assessment in transnational context, Appl. Geogr., doi:10.1016/j.apgeog.2008.10.005, in press, 2008.

Cutter, S. L.: Vulnerability to Environmental Hazards, Prog. Hum. Geog., 20, 52-539, doi:10.1177/030913259602000407, 1996.

Cutter, S. L., Mitchell, J. T., and Scott, M. S.: Revealing the Vulnerability of People and Places: A Case Study of Georgetown County, South Carolina, Ann. Assoc. Am. Geogr., 90(4), 713737, doi:10.1111/0004-5608.00219, 2000.

Cutter, S. L.: The Geography of Social Vulnerability: Race, Class, Catastrophe, Perspectives from the Social Sciences, online available at: http://understandingkatrina.ssrc.org/Cutter/, 2005.

Cutter, S. L., Barnes, L., Berry, M., Burton, C., Evans, E., Tate, J., and Webb, J.: A place-based model for understanding community resilience to natural disasters, Glob. Environ. Chang., 18, 598-606, doi:10.1016/j.gloenvcha.2008.07.013, 2008.

Dilley, M., Chen, R. S., Deichmann, U., Lerner-Lam, A. L., and Arnold, M.: Natural Disaster Hotspots, A Global Risk Analysis, World Bank, 2005.

Ebohon, B. and Schrott, L.: Modeling Mountain Permafrost Distribution. A New Permafrost Map of Austria, in: Proceedings of the Ninth International Conference on Permafrost, edited by: Kane, D. and Hinkel, K.: Fairbanks, Alaska, 397-402, 2008.

European Commission: Guidance for the analysis of Pressures and Impacts in accordance with the Water Framework Directive, Board of Water Directors, 2002a.

European Commission: Analysis of pressures and impacts the key implementation requirements of the water framework directive policy summary to the guidance document, Board of Water Directors, $2002 \mathrm{~b}$.

European Commission: Pressure and Impacts Analysis, Board of Water Directors, 2002c.

Fekete, A.: Validation of a social vulnerability index in context to river-floods in Germany, Nat. Hazards Earth Syst. Sci., 9, 393403, 2009,

http://www.nat-hazards-earth-syst-sci.net/9/393/2009/.

Flügel, W.: Hydrological Response Units (HRU's) as modelling entities for hydrological river basin simulation and their methodological potential for modelling complex environmental process systems - Results from the Sieg catchment, Die Erde, 127, 4362, 1996.
Gall, M.: Indices of Social Vulnerability to Natural Hazards: A Comparative Evaluation, $\mathrm{PhD}$, University of South Carolina, Columbia, SC, USA, 2007.

Greiving, S., Fleischhauer, M., and Lückenkötter, J.: A methodology for an integrated risk assessment of spatially relevant hazards, Journal of Environmental Planning and Management, 49(1), 1-19, doi:10.1080/09640560500372800, 2006.

Helmer, O.: The Use of the Delphi Technique in Problems of Educational Innovations, Rand Documents No. P-3499 (Santa Monica: The Rand Corporation), 1966.

Hewitt, K. and Burton, I.: The Hazardousness of a Place: A Regional Ecology of Damaging Events, Department of Geography Research publication 6, University of Toronto, Toronto, Canada, 1971.

Hufschmidt, G., Crozier, M., and Glade, T.: Evolution of natural risk: research framework and perspectives, Nat. Hazards Earth Syst. Sci., 5, 375-387, 2005, http://www.nat-hazards-earth-syst-sci.net/5/375/2005/.

IPCC (Intergovernmental Panel on Climate Change): Climate Change 2001: Synthesis report, World Meteorological Organization, UN Environment Programme, Geneva, 2001a.

IPCC (Intergovernmental Panel on Climate Change): Climate Change 2001: Impacts, Adaptation and Vulnerability. Contribution to the Working Group I to the third assessment report of the Intergovernmental Panel on Climate Change (IPCC), Cambridge University Press, Cambridge, $2001 \mathrm{~b}$.

Jiang, H. and Eastman, J. R.: Application of fuzzy measures in multi-criteria evaluation in GIS, Int. J. Geogr. Inf. Sci., 14(2), 173-184, doi:10.1080/136588100240903, 2000.

Kienberger, S., Lang, S., and Tiede, D.: Socio-economic vulnerability units - modelling meaningful spatial units, Proceedings of the GIS Research UK 16th Annual conference GISRUK 2008, Manchester, UK, 2008.

Kienberger, S., Amoaka Johnson, F., Zeil, P., Hutton, C. W., Lang, S., and Clark, M.: The integration of Land Use/Land Cover data within the modelling of socio-economic vulnerabilities. Proceedings of the 10th High Mountain Remote Sensing and Cartography Symposium, Kathmandu, Nepal, 2009.

Lang, S. and Blaschke, T.: Bridging remote sensing and GIS - what are the most supportive pillars?, in: International Archives of Photogrammetry, edited by: Lang, S. and Blaschke, T., Remote Sensing and Spatial Information Sciences vol. XXXVI-4/C42, CD-ROM, 2006.

Lang, S.: Object-based image analysis for remote sensing applications: modeling reality - dealing with complexity, in: ObjectBased Image Analysis - Spatial concepts for knowledge-driven remote sensing applications, edited by: Blaschke, T., Lang, S., Hay, G. J., et al., New York, Springer, USA, 3-28, 2008.

Lang, S., Zeil, P., Kienberger, S., and Tiede, D.: Geons - policyrelevant geo-objects for monitoring high-level indicators, in: Geospatial Crossroads@ @I_Forum '08, edited by: Car, A., Griesebner, G. and Strobl, J., Proceedings of the Geoinformatics Forum Salzburg, 180-185, 2008.

Leidel, M.: Enhancement of the concept of vulnerability units and its integration into water resources management, MSc., TU Munich, Germany, 2008

Lieb, G. K.: High-Mountain permafrost in the Austrian Alps (Europe). Proceedings of the 7th International Conference on Permafrost, Yellowknife, Canada, 23-27 June, 663-668, 1998. 
Malczewski, J.: GIS and Multicriteria Decision Analysis, John Wiley \& Sons, 1999.

Malczewski, J.: On the Use of Weighted Linear Combination Method in GIS: Common and Best Practice Approaches, Transactions in GIS, 4(1), 5-22, doi:10.1111/1467-9671.00035, 2000.

Mennis, J.: Generating Surface Models of Population Using Dasymetric Mapping, The Prof. Geogr., 55(1), 31-42, doi:10.1111/0033-0124.10042, 2003.

November, V.: Spatiality of risk, Environ. Plann. A, 40, 1523-1527, doi:10.1068/a4194, 2008.

Oberndorfer, S., Fuchs, S., Rickenmann, D., and Andrecs, P.: Vulnerabilitätsanalyse und monetäre Schandensbewertung von Wildbachereignissen in Österreich, Schriftenreihe des Bundesforschungs- und Ausbildungszentrums für Wald, Naturgefahren und Landschaft, 139, 2007.

Openshaw, S.: The modifiable areal unit problem, Concepts and techniques in modern geography, 38, 1984

Robinson, V. B.: A perspective on the fundamentals of Fuzzy Sets and their Use in Geographic Information Systems, Transactions in GIS, 7(1), 3-30, doi:10.1111/1467-9671.00127, 2003.

Schneiderbauer, S.: Risk and Vulnerability to Natural Disasters - from Broad View to Focused Perspective: Theoretical background and applied methods for the identification of the most endangered populations in two case studies at different scales, Dissertation at the Fachbereich Geowissenschaften der Freien Universität Berlin, Germany, 2007.

Smeets, E. and Weterings, R.: Environmental Indicators: Typology and Overview, Technical report no. 25, Copenhagen: European Environment Agency, 1999.

Smith, B.: On drawing lines on a map, in: Proceedings of COSIT 1995, Spatial Information Theory, edited by: Frank, A., Kuhn, W., and Mark, D. M., Springer, Berlin, 475-484, 1995.

Smith, B. and Mark, D. M.: Ontology and Geographic Kinds, Proceedings, International Symposium on Spatial Data Handling (SDH'98), Vancouver, Canada, 12-15 July, 308-320, 1998.
Stalzer, W.: Bestandsaufnahme und Beurteilung der gesamten Hochwasserfolgen, ÖWAV Symposium, März 2003, Wien, 2003.

Tiede, D. and Lang, S.: Analytical 3-D views and virtual globes - scientific results in familiar spatial context, ISPRS Journal of Photogrammetry and Remote Sensing, Theme issue: Visualization and Exploration of Geospatial Data, pages pending, in press, 2009.

Thomalla, F., Downing, T., Spanger-Siegfried, E., Han, G., and Rockström, J.: Reducing hazard vulnerability: towards a common approach between disaster risk reduction and climate adaptation, Disasters, 30(1), 39-48, doi:10.1111/j.14679523.2006.00305.x, 2006.

Thywissen, K.: Components of Risk. A Comparative Glossary, UNU Institute for Environment and Human Security, Source Nr. 2, 2006.

Turner II, B. L., Matson, P. A., McCarthy, J. J., Corell, R. W., Christensen, L., Eckley, N., Hovelsrud-Broda, G. K., Kasperson, J. X., Kasperson, R. E., Luers, A., Martello, M. L., Mathiesen, S., Naylor, R., Polsky, C., Pulsipher, A., Schiller, A., Selin, H., and Tyler, N.: Illustrating the coupled human-environment system for vulnerability analysis: Three case studies, P. Natl. Acad. Sci. USA., 100, 8080-8085, doi:10.1073/pnas.1231334100, 2003.

UN/ISDR (International Strategy for Disaster Reduction): Living with Risk: A Global Review of Disaster Reduction Initatives, Geneva: UN Publications, 2004.

Villagrán, J. C. V.: Vulnerability: a conceptual and methodological review, UNU Institute for Environment and Human Security, Source Nr. 4, 2006.

Wonka, E.: Regionalstatistik in Österreich. Von der Tabelle zu räumlicher Analyse und Visualisierung, in: Salzburger Geographische Arbeiten, edited by: Strobl, J., Band 39, Salzburg und Wien, 2006 